\title{
Associação dos herbicidas diclosulam e glyphosate na dessecação visando o controle residual de plantas daninhas na cultura da soja ${ }^{1}$
}

\author{
Association of the herbicides diclosulam and glyphosate on soybeans burndown \\ aiming residual control of weeds
}

\author{
Tássia Tuane Moreira dos Santos²; Paulo César Timossi³; Suzete Fernandes Lima ${ }^{4}$; Dênio \\ Celestino Gonçalves ${ }^{5}$; Marcus Vinícius Santana ${ }^{6}$
}

\begin{abstract}
Resumo - A associação dos herbicidas glyphosate e diclosulam na dessecação pode diminuir a presença de plantas daninhas por maior período, favorecendo assim o desenvolvimento e a produtividade das plantas de soja. Objetivou-se verificar a eficiência do herbicida diclosulam associado ao glyphosate, na dessecação para plantio direto da cultura de soja RR, cultivada no sistema plante e aplique. A cobertura vegetal presente foi Urochloa ruziziensis com 4,4 tha ${ }^{-1}$, distribuída uniformemente sobre a área experimental. $\mathrm{O}$ delineamento experimental utilizado foi o de blocos ao acaso com três tratamentos e 4 repetições. Os tratamentos constituíram-se na aplicação de glyphosate a 1,2 $\mathrm{kg} \mathrm{ha}^{-1}$ de equivalente ácido (e.a.) + diclosulam a $25,2 \mathrm{~g} \mathrm{ha}^{-1}$ de ingrediente ativo (i.a.) em pré-semeadura da cultura sem a aplicação complementar, glyphosate a $1,2 \mathrm{~kg} \mathrm{ha}^{-1}$ de e.a. + diclosulam a $25,2 \mathrm{~g} \mathrm{ha}^{-1}$ de i.a. em pré-semeadura da cultura + glyphosate a $1,2 \mathrm{~kg} \mathrm{ha}^{-1}$ e.a. em complementação e glyphosate a $1,2 \mathrm{~kg} \mathrm{ha}^{-1}$ de e.a. em pré-semeadura + glyphosate a $1,2 \mathrm{~kg} \mathrm{ha}^{-}$ ${ }^{1}$ de e.a. em complementação. Foram avaliados os seguintes parâmetros: reinfestação inicial e densidade relativa de plantas daninhas aos 31 dias após a dessecação, reinfestação de plantas daninhas no período da colheita, dificuldade de colheita mecanizada, número de vagens por planta, peso de 1000 grãos e produtividade de grãos. A associação do herbicida diclosulam ao glyphosate auxilia no manejo inicial da comunidade infestante no cultivo da soja, sem, no entanto, dispensar a aplicação complementar do herbicida glyphosate.
\end{abstract}

Palavras-chaves: cobertura vegetal; Glycine max; mistura de herbicidas; plantio direto

Abstract - The association of glyphosate and diclosulam in burndown can reduce the presence of weeds for a longer period, thus promoting the development and productivity of soybean plants. The objective was verify if the efficiency of the herbicide diclosulam associated with glyphosate, in burndown for direct seeding, in the seed bank of weeds in soybean grown in the plant system and apply. The straw present was Urochloa ruziziensis at $4.4 \mathrm{t} \mathrm{ha}^{-1}$ of dry mass, uniformly distributed over the experimental area. The experimental design was randomized blocks design

\footnotetext{
${ }^{1}$ Recebido para publicação em 07/04/2016 e aceito em 02/06/2016.

${ }^{2}$ Eng. Agr. Mestranda em Agronomia - Programa de Pós-Graduação em Agronomia, Universidade Federal de Goiás, Goiânia, GO, Brasil. Rodovia Goiânia/Nova Veneza, Km 0 - CEP 74001-970 - Cx. Postal 131. E-mail: <tassiatuane@hotmail.com>.

${ }^{3}$ Professor na Universidade Federal de Goiás - Regional Jataí. Jataí, Goiás, Brasil.

${ }^{4}$ Eng. Agr. Doutoranda em Ciências Agrárias/Agronomia no IFGoiano - Campus Rio Verde, Rio Verde, Goiás, Brasil.

${ }^{5}$ Graduando em Agronomia na Universidade Federal de Goiás - Regional Jataí. Jataí, Goiás, Brasil.

${ }^{6}$ Eng. Agr. Doutorando em Agronomia- Programa de Pós-Graduação em Agronomia, Universidade Federal de Goiás, Goiânia, Goiás, Brasil.
} 
with three treatments and four replications. The treatments consisted in the application of glyphosate at $1.2 \mathrm{~kg} \mathrm{ha}^{-1}$ acid equivalent (a.e.) + diclosulam $25.2 \mathrm{~g} \mathrm{ha}^{-1}$ active ingredient (a.i.) in pre-sowing without the complementary application, glyphosate at $1.2 \mathrm{~kg} \mathrm{ha}^{-1}+$ diclosulam $25,2 \mathrm{ha}^{-}$ ${ }^{1}$ in pre-sowing of the culture $+1,2 \mathrm{~kg} \mathrm{ha}^{-1}$ of glyphosate in complementation and glyphosate at 1.2 $\mathrm{kg} \mathrm{ha}^{-1}$ in pre-sowing + glyphosate at $1.2 \mathrm{~kg} \mathrm{ha}^{-1}$ in complementation. It were evaluated the initial reinfestation and relative density of weeds at 31 days after burndown, reinfestation of weeds at harvest time, difficulty of mechanized harvesting, number of pods per plant, 1000 grain weight and productivity. The association of the herbicides glyphosate and diclosulam assists in the initial management of weeds in soybean, without, however, dispense the complementary application of glyphosate.

Keywords: vegetation cover; Glycine max; herbicides mixture; no-tillage

\section{Introdução}

O plantio direto ganhou espaço entre os produtores de soja nos últimos anos tanto pelo fato de melhorar as propriedades físicas e químicas do solo como auxiliar no manejo integrado de plantas daninhas. Estima-se em aproximadamente 32 milhões de hectares a área cultivada sob este sistema de plantio (Motter e Almeida, 2015). A cobertura morta, quando bem formada e se distribuída uniformemente sobre a superfície do solo, age física e mecanicamente sobre o banco de sementes de plantas daninhas, diminuindo assim a taxa de germinação (Pitelli e Durigan, 2001). O sucesso na dessecação é imprescindível para o desenvolvimento adequado da cultura neste sistema de cultivo, sendo que quando o herbicida utilizado na dessecação não apresenta efeito residual sobre o banco de sementes de plantas daninhas, outras medidas de manejo são necessárias, como a aplicação de herbicidas em pós-emergência da cultura.

O glyphosate é largamente utilizado na dessecação das plantas de cobertura e proporciona controle eficiente de um amplo espectro de plantas daninhas, mas não apresenta efeito residual (Albrecht et al., 2012). Neste caso, as associações com herbicidas com efeito residual têm sido bastante utilizadas (Osipe et al., 2010). Misturas de herbicidas para o controle de plantas daninhas têm sido consideradas uma técnica promissora, pois pode controlar maior número de espécies (Vieira Júnior et al., 2015) e prevenir a resistência destas espécies à moléculas herbicidas (Owen e Zelaya, 2005). Controle satisfatório foi alcançado pelas misturas de glyphosate + haloxyfop-methyl, glyphosate + fenoxaprop-pethyl + clethodim e glyphosate + tepraloxydim, glyphosate + saflufenacil no controle de capim amargos, buva resistente ao glyphosate e corda de viola (Melo et al., 2012; Dalazen et al., 2015; Agostineto, 2016). No entanto, deve-se atentar ao fato de que certas associações podem reagir negativamente com o glyphosate (Alonso et al., 2010). Vidal et al. (2016) relataram antagonismo entre glyhosate e herbicidas, principalmente de contato. Efeito antagônico também foi observado na mistura de glyhosate+glufosinate, causando redução no controle de Abutilon theophrasti, Chenopodium álbum, Setaria faber e Eleusine indica (Chuah et al., 2008; Bethke et al., 2013).

Outra alternativa que tem sido utilizada para suprir a ausência do efeito residual deste herbicida é o uso de pulverizações sequenciais. Devido à existência de genótipos resistentes aos herbicidas inibidores de EPSPS, é indicado que haja rotações de mecanismos de ação, além de outras práticas de manejo de plantas daninhas, para minimizar a ocorrência do problema em nosso país (Alonso et al., 2013). Sendo assim, a associação do glyphosate à herbicidas com diferentes mecanismos de ação e que apresentem efeito residual passa a ser uma opção viável para o manejo das plantas daninhas da soja.

O diclosulam é um herbicida seletivo do grupo das sulfonanilidatriazolopirimidinas, 
recomendado para o controle de plantas daninhas eudicotiledôneas em pré-emergência na cultura da soja (Rodrigues e Almeida, 2011). Este herbicida possui efeito residual, o que contribui para evitar fluxos de emergência de plantas daninhas no estabelecimento inicial da cultura de soja. Segundo Lavorenti el al. (2003), em solo sob plantio direto, o diclosulam tem meia vida de 67 dias. Portanto, o uso deste tipo de herbicida pode promover a redução da interferência de plantas daninhas no início do ciclo de desenvolvimento da cultura, contribuindo para o fechamento mais efetivo e precoce da soja (Jaremtchuk et al., 2008). O diclosulam, tanto na ausência como na presença de palhada, foi eficaz no controle das plantas daninhas Ipomoea grandifolia e Sida rhombifolia em casa de vegetação (Carbonari et al., 2008). Portanto, este herbicida é uma alternativa para ser utilizado em associação com o glyphosate na dessecação.

A associação destes herbicidas pode ser eficiente no controle de plantas daninhas da cultura da soja. Sendo assim, objetivou-se avaliar a eficiência da associação de diclosulam ao glyphosate no manejo de pré-semeadura da soja sobre a infestação das plantas daninhas desta cultura.

\section{Material e Métodos}

O experimento foi conduzido na região sudoeste do estado de Goiás, no município de Jataí. A região conta com uma altitude de cerca de 700 metros e precipitação pluviométrica anual entre 1400 a 1800 milímetros, distribuída entre os meses de setembro a abril. A temperatura média deste período está em torno de $25^{\circ} \mathrm{C}$. Os dados climatológicos do período de condução (Figura 1) foram obtidos na estação agrometeorológica do Instituto Nacional de Meteorologia (INMET) lotada a $1000 \mathrm{~m}$ da área experimental (coordenadas: S $17^{\circ} 55^{\prime} 409^{\prime \prime}$ e WO 51 $1^{\circ} 42^{\prime}$ 575"). O solo da área é classificado como Latossolo Vermelho distroférrico, com textura argilosa.

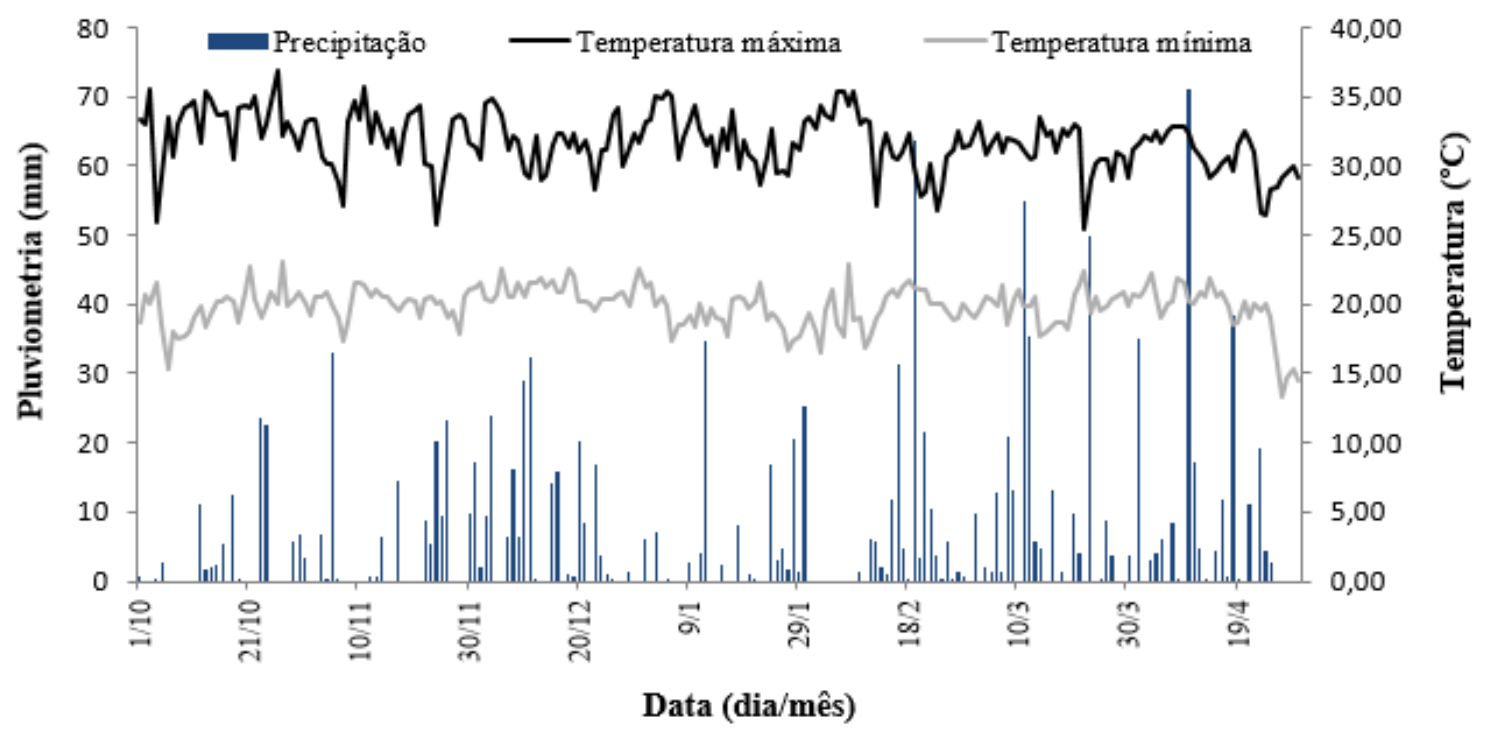

Figura 1. Dados de precipitações, temperaturas máxima e mínima durante a condução da pesquisa. INMET, 2014.

A cultivar de soja adotada foi a Monsoy 9144 RR, de ciclo tardio (140 dias), semeada em 7 de novembro de 2013, no sistema planteaplique sobre $4,4 \mathrm{t} \mathrm{ha}^{-1}$ de cobertura vegetal proporcionada por Urochloa ruziziensis semeada a 500 pontos de VC (valor cultural) por hectare 3 meses antes da dessecação. A massa seca foi determinada a partir da coleta das 
plantas presentes numa área de $0,25 \mathrm{~m}^{2}$, as plantas foram cortadas rente ao solo e o peso de massa seca foi obtido após a secagem das amostras em câmara de circulação forçada de ar, a $65^{\circ} \mathrm{C}$, por 72 horas (Lima et al., 2014). Na semeadura da cultura da soja foi adotada a adubação em sulco com $350 \mathrm{~kg} \mathrm{ha}{ }^{-1}$ do fertilizante NPK na formulação 04-20-18 e com população média estimada em 200 mil plantas $\mathrm{ha}^{-1}$. Os herbicidas utilizados foram o glyphosate (Roundup WG, 792,5 $\mathrm{g} \mathrm{Kg}^{-1}$ de e.a., WG, Monsanto do Brasil) e o diclosulam (Spider 840 WG, $840 \mathrm{~g} \mathrm{~kg}^{-1}$ de i.a., WG, Dow AgroSciences).

O delineamento experimental adotado foi o de blocos ao acaso, com 3 tratamentos e 4 repetições. A área de cada parcela experimental foi de $20 \mathrm{~m}^{2}(4 \mathrm{~m}$ de largura $\mathrm{x} 5 \mathrm{~m}$ de comprimento). Os tratamentos basearam-se na aplicação de: glyphosate a $1,2 \mathrm{~kg} \mathrm{ha}^{-1}$ de equivalente ácido (e.a.) + diclosulam a 25,2 g $\mathrm{ha}^{-1}$ de ingrediente ativo (i.a.) em pré-semeadura da cultura sem a aplicação complementar $(\mathrm{G}+$ $\mathrm{S})$; glyphosate a $1,2 \mathrm{~kg} \mathrm{ha}^{-1}$ e.a + diclosulam a 25,2 $\mathrm{g} \mathrm{ha}^{-1}$ i.a. em pré-semeadura da cultura + glyphosate a 1,2 $\mathrm{kg} \mathrm{ha}^{-1} \mathrm{e} . \mathrm{a}$. em complementação $(\mathrm{G}+\mathrm{S}+\mathrm{G})$; glyphosate a $1,2 \mathrm{~kg} \mathrm{ha}^{-1}$ e.a. em présemeadura + glyphosate a $1,2 \mathrm{~kg} \mathrm{ha}^{-1}$ e.a. em complementação $(\mathrm{G}+\mathrm{G})$. A complementação do glyphosate foi realizada aos 35 dias após a semeadura, com a soja no estágio de desenvolvimento V4.

As pulverizações com os herbicidas foram realizadas com pulverizador pressurizado por $\mathrm{CO}_{2}$ acoplado à barra de $2 \mathrm{~m}$, com quatro bicos (espaçamento de $0,5 \mathrm{~m}$ entre bicos) e pontas do tipo TT110015, com classe de gotas média. O volume de calda utilizado foi de $150 \mathrm{~L}$ $\mathrm{ha}^{-1}$. Durante a aplicação de dessecação a temperatura variou entre $29-30^{\circ} \mathrm{C}$ e a umidade do ar de 46 a 61. Já na complementação a temperatura permaneceu em $30^{\circ} \mathrm{C}$ e a umidade relativa do ar entre 69 e 80\%. Nas duas aplicações a velocidade do vento se manteve de 0 a $4,7 \mathrm{~km} \mathrm{~h}^{-1}$.

No tratamento fitossanitário da cultura da soja foram realizadas três aplicações de inseticidas e fungicidas. A principal doença na cultura foi a ferrugem asiática (Phakopsora pachyrhizi), a qual apresentou infestação intensa. A primeira aplicação foi realizada em 10/01/2014, com os seguintes produtos: $60 \mathrm{~g} \mathrm{ha}^{-}$ ${ }^{1}$ de picoxystrobina, $24 \mathrm{~g} \mathrm{ha}^{-1}$ de ciproconazol, $100 \mathrm{~g} \mathrm{ha}^{-1}$ de profenofós, $10 \mathrm{~g} \mathrm{ha}^{-1}$ de lufenuron $+0,3 \% \mathrm{v} / \mathrm{v}$ de óleo mineral. A segunda aplicação foi realizada em 25/01/2014, com os seguintes produtos: $60 \mathrm{~g} \mathrm{ha}^{-1}$ de picoxystrobina, $24 \mathrm{~g} \mathrm{ha}^{-1}$ de ciproconazol, $215 \mathrm{~g} \mathrm{ha}^{-1}$ de metomil $+0,3 \%$ v/v de óleo mineral. A terceira aplicação foi realizada em 10/02/2014 com os seguintes produtos: $93,1 \mathrm{~g} \mathrm{ha}^{-1}$ de piraclostrobina, $35 \mathrm{~g} \mathrm{ha}^{-}$ ${ }^{1}$ de epoxiconazol e $750 \mathrm{~g} \mathrm{ha}^{-1}$ de acefato. A metodologia aplicada no manejo fitossanitário foi adaptada de Araújo et al. (2012).

Foram avaliados os seguintes parâmetros: reinfestação inicial e densidade relativa de plantas daninhas aos 31 dias após a dessecação, reinfestação de plantas daninhas no período da colheita, dificuldade de colheita mecanizada, número de vagens por planta, peso de 1000 grãos e produtividade de grãos. Sendo que os parâmetros de produção foram avaliados afim de averiguar se a presença de plantas daninhas reinfestantes influenciariam na produtividade da soja. A reinfestação inicial e densidade relativa foram determinadas com auxílio de quadro metálico de $0,25 \mathrm{~m}^{2}$, lançado aleatoriamente por três vezes em cada unidade experimental, sendo as plantas daninhas presentes nesta área identificadas e contabilizadas.

A reinfestação de plantas daninhas por ocasião da colheita foi realizada por escala visual e percentual de notas adaptada de ALAM (1974), atribuindo-se 0\% quando não havia presença de plantas daninhas e $100 \%$ quando toda a área da parcela estava coberta por plantas daninhas. Avaliou-se ainda a dificuldade de colheita mecanizada, atribuindo-se notas de 0 a 100 com base na porcentagem de cobertura por plantas daninhas na área útil das parcelas (Nunes et al., 2010). A nota 0 foi adotada para as parcelas nas quais poderiam existir plantas daninhas, porém a colheita não seria 
prejudicada, enquanto que nas parcelas onde era visivelmente impossível de se realizar colheita mecanizada atribuiu-se nota 100 .

A colheita foi realizada manualmente, em 2 de abril de 2014, aos 150 DAS. Foram coletadas as plantas de 4 linhas centrais de 2,5 $m$ de comprimento, em cada parcela experimental. Após a correção de umidade para $13 \%$, obteve-se a produtividade $\left(\mathrm{kg} \mathrm{ha}^{-1}\right)$. As avaliações do número de vagens por planta foram realizadas em uma subamostra de 5 plantas tomadas ao acaso dentro da área útil de cada unidade experimental.

A normalidade e homocedasticidade dos dados foram verificadas com os testes de Kolmogorov-Smirnov e Levene. Os dados de dificuldade de colheita não atenderam aos pressupostos da ANOVA, sendo submetidos à transformação $\sqrt{X+1}$. Já os dados de reinfestação inicial foram transformados com a equação $\log 10 \quad(\mathrm{x}+1)$. Os dados das características agronômicas da soja foram submetidas à análise de variância pelo teste $\mathrm{F}$, utilizando-se o software estatístico R, e posteriormente, quando necessário, à comparação de médias pelo teste Tukey a $p<0,05$. A densidade relativa foi calculada de acordo com as equações propostas por MüellerDombois e Ellenberg (1974).

\section{Resultados e Discussão}

O picão preto (Bidens pilosa) foi a espécie dominante na área, com densidade relativa acima de $74 \%$ em todos os tratamentos (Tabela 1). Esta planta daninha apresenta adaptação aos ambientes agrícolas, além de grande produção de sementes e mecanismos de dormência que garantem a sua germinação (Carmona e Bôas, 2001). Também foram identificadas as seguintes espécies em menor densidade: trapoeraba (Commelina benghalensis), erva-de-santa-luzia (Chamaesyce hirta), braquiária (Brachiaria ruziziensis), capim colchão (Digitaria horizontalis), e buva (Conyza canadensis).

Tabela 1. Densidade relativa de plantas daninhas, 31 dias após a dessecação. Jataí (GO), 2014.

\begin{tabular}{lcccccc}
\hline \multicolumn{1}{c}{ Tratamentos } & BIPDI* & COMBE & BRARU & DIGHO & EPHHS & ERICA \\
& $(\%)$ & $(\%)$ & $(\%)$ & $(\%)$ & $(\%)$ & 0,31 \\
\hline $\mathrm{G}+\mathrm{S}^{2}$ & 78,75 & 10,31 & 7,19 & 0,94 & 2,50 & 0,97 \\
$\mathrm{G}+\mathrm{S}^{1}+\mathrm{G}^{2}$ & 81,35 & 7,54 & 4,17 & 0,20 & 3,97 & 2,78 \\
$\mathrm{G}+\mathrm{G}^{2}$ & 74,11 & 10,78 & 2,63 & 1,45 & 6,44 & 4,60 \\
\hline
\end{tabular}

${ }^{1}$ Sem complementação, ${ }^{2}$ Com complementação de glyphosate aos 35 dias após dessecação. *Código internacional: BIDPI - Bidens pilosa; COMBE - Commelina benghalensis; BRARU - Brachiaria ruziziensis; DIGHO - Digitaria horizontalis; EPHHS - Chamaesyce hirta; ERICA - Conyza canadenses.

O tratamento $\mathrm{G}+\mathrm{G}$ possibilitou a maior reinfestação inicial, com 63,58 plantas $\mathrm{m}^{-2}$, significativamente diferente dos demais (Tabela 2). Muitas espécies de plantas daninhas possuem sementes com dormência em vários graus, afim de garantir emergência sucessiva (Fogliatto et al.2010apud Markus et al., 2012). Plácido et al. (2015) também observaram decréscimo na porcentagem de controle de plantas daninhas quando o manejo de dessecação foi realizado apenas com glyphosate. Pois, a ausência do herbicida com efeito residual na dessecação permite a germinação do banco de sementes de plantas daninhas alguns dias após a dessecação.

Por outro lado, as menores médias de reinfestação inicial foram proporcionadas pelos tratamentos $\mathrm{G}+\mathrm{S}$ e $\mathrm{G}+\mathrm{S}+\mathrm{G}$, que apresentaram em média 20 plantas $\mathrm{m}^{-2}$. Estes resultados corroboram com Oliveira Neto et al. (2013) que observaram que a mistura glyphosate + diclosulam foi eficiente para o controle de Conyza spp. na dessecação de manejo pré-semeadura da soja, além disso, suprimiu adequadamente o desenvolvimento inicial dos novos fluxos de Digitaria spp., Sida rhombifolia e Ipomoea triloba. A adição de 
glifosato ao herbicida saflufenacil também preveniu o rebrote e a dispersão de novas sementes de buva (Dalazen et al., 2015). Resultados semelhantes também foram encontrados por Byker et al. (2013) que observaram a alta eficiência da mistura de glyphosate com saflufenacil aplicada em présemeadura no controle de buva, quatro semanas após a pulverização.

Tabela 2. Médias de reinfestação inicial, reinfestação na colheita e dificuldade de colheita. Jataí (GO), 2014.

\begin{tabular}{lccc}
\hline & Reinfestação inicial $\left(\mathrm{m}^{2}\right)$ & Reinfestação na colheita (\%) & $\begin{array}{c}\text { Dificuldade } \\
\text { de colheita }(\%)\end{array}$ \\
\hline F blocos & 0,53667 & 0,34994 & 0,83797 \\
\hline F tratamentos & $0,00434^{*}$ & $0,00004 * *$ & $0,00000^{* *}$ \\
\hline $\mathrm{G}+\mathrm{S}^{2}$ & $20,5 \mathrm{~A}$ & $53,3 \mathrm{~A}$ & $55,75 \mathrm{~A}$ \\
$\mathrm{G}+\mathrm{S}^{1}+\mathrm{G}^{2}$ & $22,3 \mathrm{~A}$ & $1,3 \mathrm{~B}$ & $0 \mathrm{~B}$ \\
$\mathrm{G}+\mathrm{G}^{2}$ & $63,58 \mathrm{~B}$ & $1,4 \mathrm{~B}$ & $0 \mathrm{~B}$ \\
\hline $\mathrm{CV}(\%)$ & 22,74 & 34,82 & 31,72 \\
\hline
\end{tabular}

${ }^{1}$ Sem complementação com glyphosate; ${ }^{2}$ Com complementação de glyphosate aos 35 dias após dessecação. ${ }^{*}$ Médias seguidas pela mesma letra, na coluna, não diferem entre si pelo teste de Tukey a 5\% de probabilidade.

Os tratamentos que receberam complementação com glyphosate $(\mathrm{G}+\mathrm{S}+\mathrm{G}$ e $\mathrm{G}+\mathrm{G})$ resultaram em menos de $2 \%$ de reinfestação por ocasião da colheita (Tabela 2). Nestes tratamentos a complementação juntamente com o fechamento das entrelinhas promovido pela cultura da soja, garantiu a supressão de plantas daninhas. Já o tratamento $\mathrm{G}+\mathrm{S}$ apresentou a maior média de reinfestação por ocasião da colheita, com cobertura vegetal de $53 \%$ da área útil das parcelas cobertas por plantas daninhas, diferindo estatisticamente dos demais. Oliveira Jr. (2002) observaram comportamento semelhante já que o diclosulam não evitou a germinação do banco de sementes.

O uso de herbicidas em complementação após a aplicação de misturas de glyphosate com outros herbicidas também é indicado por Melo et al. (2012). Isto indica que a sementeira de plantas daninhas consegue germinar com sucesso com a diminuição do efeito residual dos herbicidas. Como o efeito residual do diclosulam é de 67 dias, quando aplicado em área de plantio direto (Lavorenti, 2013), a diminuição deste efeito associado a ausência da complementação com glyphosate permite o sucesso da germinação da sementeira de plantas daninhas e a consequente reinfestação da área.
$\mathrm{O}$ tratamento $\mathrm{G}+\mathrm{S}$ apresentou maior porcentagem de dificuldade de colheita (Tabela 2), o que está associado a maior taxa de reinfestação constatada por ocasião da colheita. As parcelas deste tratamento apresentaram média de $50 \%$ de dificuldade de colheita sendo que a maior parte deste total foram de braquiária. Apesar de não constituir as características de produção, nota-se que a cobertura vegetal proporcionada pela comunidade infestante no momento da colheita pode acarretar em dificuldade para a colheita mecanizada (Timossi e Durigan, 2006).

Além disso, a presença das plantas daninhas pode atrasar a senescência das plantas de soja, o que prejudica a colheita mecanizada, uma vez que a umidade ideal dos grãos para colheita é de $12-14 \%$. A ausência da aplicação do herbicida de pós-emergência permitiu que plantas da própria cobertura vegetal reinfestasse a área pela presença de rebrotes e/ou fluxos de emergência de sementes presentes no banco de sementes. Oliveira Jr. et al. (2002) observaram reinfestação a partir dos 42 dias após a pulverização dos herbicidas. A análise de dificuldade de colheita é extremamente importante, pois, quanto maior a dificuldade, mais danos serão causados às colhedoras e maiores perdas ocorrerão. Nos tratamentos $G+$ 
$\mathrm{S}+\mathrm{G}$ e $\mathrm{G}+\mathrm{G}$ a médias de dificuldade de colheita foi de $0 \%$ (Figura 2A), o que representa ausência de plantas daninhas por ocasião da colheita.

A presença de plantas daninhas no $\mathrm{G}+\mathrm{S}$ não interferiu expressivamente no número de vagens por planta e no enchimento dos grãos, uma vez que não houve diferença estatística entre os tratamentos nestes parâmetros (Tabela 3). No entanto, as parcelas tratadas com $\mathrm{G}+\mathrm{S}$ resultaram na menor produtividade (Tabela 3 ). Com a perda do efeito residual do diclosulam e a ausência da pulverização complementar, as plantas daninhas que foram identificadas e contabilizadas aos 31 DAD conseguiram se estabelecer e competir com a cultura, a ponto de reduzir a produtividade nas parcelas do tratamento G + S. A cultivar de soja Monsoy 7908 RR passou a ser afetada negativamente pela convivência com as plantas daninhas a partir de 25 DAE (Benedetti et al., 2009). Além disso, segundo Meschede (2004), entre 11 e 68 dias após a emergência, a interferência imposta pelas plantas daninhas promove queda de produtividade de até $38 \%$ na soja cv. BRS-133. O baixo valor de peso de 1000 grãos constatado ocorreu em função da intensa infestação de ferrugem asiática.
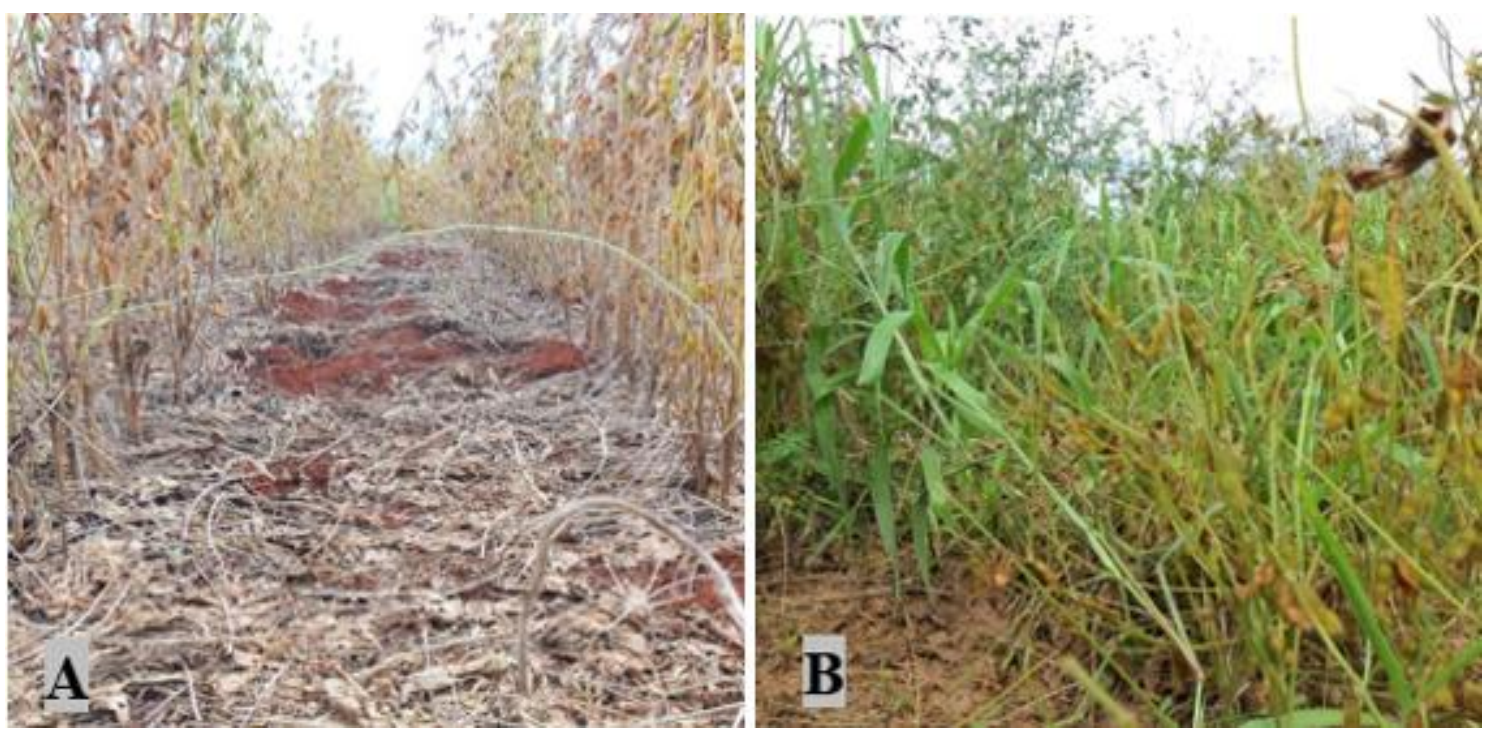

Figura 2. Aspecto visual das parcelas na ocasião da colheita da soja. A. Parcela com ausência de plantas daninhas $(\mathrm{G}+\mathrm{S}+\mathrm{G}$ e $\mathrm{G}+\mathrm{G})$; B. Parcela infestada com plantas daninhas $(\mathrm{G}+\mathrm{S})$. Jataí $(\mathrm{GO})$, 2014.

Tabela 3. Número de vagens, peso de mil grãos e produtividade de soja. Jataí (GO), 2014.

\begin{tabular}{lccc}
\hline & Número de vagens planta ${ }^{-1}$ & $\begin{array}{c}\text { Peso de 1000 grãos } \\
(\mathrm{g})\end{array}$ & $\begin{array}{c}\text { Produtividade } \\
\left(\mathrm{kg} \mathrm{ha}^{-1}\right)\end{array}$ \\
\hline F blocos & 0,58944 & 0,66984 & 0,08598 \\
\hline $\mathrm{F}$ tratamentos & $0,12097 \mathrm{~ns}$ & $0,14220 \mathrm{~ns}$ & $0,00000^{* *}$ \\
\hline $\mathrm{G}+\mathrm{S}^{2}$ & $58,8 \mathrm{~A}$ & $111,58 \mathrm{~A}$ & $721,8 \mathrm{~A}$ \\
$\mathrm{G}+\mathrm{S}^{1}+\mathrm{G}^{2}$ & $66,25 \mathrm{~A}$ & $107,75 \mathrm{~A}$ & $1198,034 \mathrm{~B}$ \\
$\mathrm{G}+\mathrm{G}^{2}$ & $65,18 \mathrm{~A}$ & $114,33 \mathrm{~A}$ & $1330,558 \mathrm{~B}$ \\
\hline $\mathrm{CV}(\%)$ & 14,61 & 7,15 & 15,98 \\
\hline
\end{tabular}

${ }^{1}$ Sem complementação com glyphosate; ${ }^{2}$ Com complementação de glyphosate aos 35 dias após dessecação. ${ }^{*}$ Médias seguidas pela mesma letra, na coluna, não diferem entre si pelo teste de Tukey a 5\% de probabilidade.

Apesar da mistura proporcionar menores dessecação, o tratamento sem a taxas de reinfestação aos 31 dias após a complementação $(G+S)$ foi insuficiente para 
evitar a reinfestação pelas plantas daninhas. Portanto, somente a mistura não assegura o controle das plantas daninhas durante o ciclo da soja. Estudos com misturas visando o controle residual sem aplicação complementar devem ser realizados considerando o uso de herbicidas com maior efeito residual. Além disso, o efeito da palhada sobre estas misturas também deve ser averiguado, uma vez que pode influenciar a eficiência dos herbicidas no controle das plantas daninhas.

\section{Conclusões}

A associação do diclosulam ao glyphosate auxilia na redução da competição inicial da comunidade infestante, mas não dispensa a aplicação complementar do herbicida glyphosate, sobre área estabelecida com a planta de cobertura Urochloa ruziziensis.

\section{Referências}

Agostineto, M.C.; Carvalho, L.B.; Ansolin, H. H.; Andrade, T.C.G.R.; Schmit, R. Synergism of mixtures of glyphosate and PROTOX inhibitor herbicides for morning-glory control. Revista de Ciências Agroveterinárias, v.15, n.1, p.8-15, 2016.

Albrecht, L.P.; Alonso, D.G.; Albrecht, A.J.P.; Oliveira Jr., R.S.; Braccini, A.L.; Constantin, J. Glyphosate e associações em pós-emergência no desempenho agronômico e na qualidade das sementes de soja RR. Planta Daninha, v.30, n.1, p.139-146, 2012.

Alonso, D.G.; Albrecht, L.P.; Albrecht, A.J.P.; Oliveira Jr., R.S.; Braccini, A.L.; Constantin, J. Seletividade de glyphosate em misturas em tanque para soja RR em aplicações sequenciais com mistura apenas na primeira ou na segunda aplicação. Planta Daninha, v.28, n.1, p.865875, 2010.

Alonso, D.G.; Constantin, J.; Oliveira Jr., R.S.; Santos, G.; Dan, H.A.; Oliveira Neto, A.M. Selectivity of glyphosate alone or in mixtures for RR soybean in sequential applications. Planta Daninha, v.31, n.1, p.203-212, 2013.

Araújo, F.G.; Rocha, M.R.; Aguiar, R.A.; Garcia, R.A.; Cunha, M.G. Management of soybean rust with fungicides for seed treatment and foliar application. Semina: Ciências Agrárias, v.33, n.1, p.2585-2592, 2012.

ASOCIACIÓN LATINO AMERICANO DE MALEZAS - ALAM. Recomendaciones sobre unificación de los sistemas de evaluación en ensayos de control de malezas. ALAM, v.1, n.1, p.35-38, 1974.

Benedetti, J.G.R.; Pereira, L.; Alves, P.L.C.A; Yamauti, M.S. Período anterior a interferência de plantas daninhas em soja transgênica. Scientia Agraria, v.10, n.4, p.289-295, 2009.

Bethke, R.K.; Molin, W.T.; Sprague, C.; Penner, D. Evaluation of the interaction between glyphosate and glufosinate. Weed Science, v.61, n.1, p.41-47, 2013.

Byker, H.P.; Soltani, N.; Robinsin, D.E.; Tardif, F.J.; Lawton, M.B.; Sikkema, P.H. Control of glyphosate-resistant Canada fleabane [Conyza canadensis (L.) Cronq.] with preplant herbicide tankmixed in soybean [Glycine max. (L.) Merr.]. Journal of Plant Science, v.93, n.3, p.659-667, 2013.

Carbonari, C.A.; Meschede, D.K.; Correa, M.R.; Velini, E.D.; Tofoli, G.R. Eficácia do herbicida diclosulam em associação com a palha de sorgo no controle de Ipomoea grandifolia e Sida rhombifolia. Planta Daninha, v.26, n.3, p.657-664, 2008.

Carmona, R.; Villas Bôas, H.D.C. Dinâmica de sementes de Bidens pilosa no solo. Pesquisa Agropecuária Brasileira, v.36, n.3, p.457-463, 2001.

Chuah, T.S.; Teh, H.H.; Cha, T.S.; Ismail, B.S. Antagonism of glufosinate ammonium activity caused by glyphosate in the tank mixtures used for control of goosegrass (Eleusine indica Gaertn.). Plant Protection Quarterly, v.23, n.3, p.116-119, 2008. 
Dalazen, G.; Kruse, N.D.; Machado, S.L.O.; Balbinot, A. Sinergismo na combinação de glifosato e saflufenacil para o controle de buva. Pesquisa Agropecuária Tropical, v.45, n.2, 2015.

INMET - Instituto Nacional de Meteorologia. Disponível em: www.inmet.gov.br Acesso em: 10 de maio de 2014.

Jaremtchuk, C.C.; Constantin, J.; Oliveira Jr., R.S.; Biffe, D.F.; Alonso, D.G.; Arantes, J.G.Z. Efeito de sistemas de manejo sobre a velocidade de dessecação, infestação inicial de plantas daninhas e desenvolvimento e produtividade da soja. Acta Scientiarum. Agronomy, v.30, n.4, p.449-455, 2008.

Lavorenti, A.; Rocha, A.A.; Prata, F.; Regitano, J.B.; Tornisielo, V.L.; Pinto, O.B. Comportamento do diclosulam em amostras de um latossolo vermelho distroférrico sob plantio direto e convencional. Revista Brasileira de Ciência do Solo, v.27, n.2, p.183-190, 2003.

Lima, S.F.; Timossi, P.C.; Almeida, D.P.; Silva, U.R. Fitossociologia de plantas daninhas em convivência com plantas de cobertura. Revista Caatinga, v.27, n.2, p.37-47, 2014.

Markus, C.; Merotto Jr., A.; Barcelos, J.A.N.; Nunes, A.L. Avaliação da dormência de sementes em populações de arroz cultivado e arroz vermelho. In: Congresso Brasileiro da Ciência de Plantas Daninhas: na era da biotecnologia, 18, 2012, Campo Grande. Sociedade Brasileira da Ciência das Plantas Daninhas. Anais. 2012. p. 365-369.

Melo, M.S.C.; Rosa, L.E; Caio, A.C.G.B; Nicolai, M.; Christoffoleti, P.J. Controle de plantas daninhas e seletividade de diclosulam aplicado em pré-emergência na cultura da soja. Revista Brasileira de Herbicidas, v.11, n.2, p.195-203, 2012.

Meschede, D.K.; Oliveira Jr., R.S.; Constantin, J.; Scapim, C.A. Period before weed interference in soybean: a case-study under low crop density and twofold checks. Planta Daninha, v.22, n.2, 2004.
Motter, P.; Almeida, H.G. Plantio direto: A tecnologia que revolucionou a agricultura brasileira. Foz do Iguaçu: Parque Itaipu, 2015. $144 p$.

Mueller-Dombois, D.; Ellenberg, H. Aims and methods of vegetation ecology. New York: John Wileye Sons, 1974. 547 p.

Nunes, A.S.; Timossi, P.C.; Pavani, M.C.M.O. D.; Alves, P.L.C.A. Formação de cobertura vegetal e manejo de plantas daninhas na cultura da soja em sistema plantio direto. Planta Daninha, v.28, n.4, p.727-733, 2010.

Oliveira Jr., R.S.; Constantin, J.; Meschede, D.K.; Maciel, C.D.G. Controle de plantas daninhas e seletividade de diclosulam aplicado em pré-emergência na cultura da soja. Revista Brasileira de Herbicidas, v.3, n.1, p.69-74, 2002.

Oliveira Neto, A.M.; Constantin, J.; Oliveira Jr., R.S.; Guerra, N.; Braz, G.B.P.; Vilela, L.M.S. et al. Sistemas de dessecação em áreas de trigo no inverno e atividade residual de herbicidas na soja. Revista Brasileira de Herbicidas, v.12, n.1, p.14-22, 2013.

Osipe, J.B.; Ferreira, C.; Osipe, R.; Boiko, W.A.; Osipe, P.B.; Baldini, V. Flumioxazin e chlorimuron-ethyl no plantio direto na cultura da soja. In: Congresso Brasileiro da Ciência das Plantas Daninhas, 27. Ribeirão Preto. Anais. 2010, p.1868-1872.

Owen, M.D.K.; Zelaya, I.A. Herbicide-resistant crops and weed resistance to herbicides. Pest Management Science, v. 61, n.3, p. 301-311, 2005.

Pitelli, R.A.; Durigan, J.C. Ecologia das plantas daninhas no sistema plantio direto. In: Rossello, R.D. Siembra directa em el Cono Sur. Montevideo: PROCISUR, p. 203-210, 2001.

Placido, H.F.; Albrecht, L.P.; Krenchinski, F.H.; Albrecht, A.J.P.; Korber, A.H.C.; Tessele, A. et al. Desiccants application season in preemergence in conventional soybeans. Revista Brasileira de Herbicidas, v.14, n.2, p.93-102, 2015. 
Rodrigues, B.N.; Almeida, F.S. Guia de herbicidas. $6^{\mathrm{a}}$ ed. Londrina. 2011. $591 \mathrm{p}$.

Timossi, P.C.I; Durigan, J.C. Manejo de convolvuláceas em dois cultivares de soja semeada diretamente sob palha residual de cana crua. Planta Daninha, v.24, n.1, p.91-98, 2006.

Vidal, R.A.; Queiroz, A.R.S. de; Trezzi, M.M.; Kruse, N.D. Association of glyphosate with other agrochemicals: the knowledge synthesis. Revista Brasileira de Herbicidas, v.15, n.1, p.39-47, 2016.

Vieira Júnior, N.S.; Jakelaitis, A.; Cardoso, I.S; Rezende, P.N.; Moraes, N.C.; Araújo, V.T. et al. Associação de herbicidas aplicados em pósemergência na cultura do milho. Global Science and Technology, v.8, n.1, p.1-8, 2015. 